\title{
To Control Electrical MCBs using Hand Gesture Recognition
}

\author{
Sangeeta ${ }^{1}$, Dr. Bhupesh Kumar ${ }^{2}$ \\ ${ }^{1,1}$ M.Tech Student, Department of CSE, RIET, M.D. University, Rohtak, Haryana, India \\ ${ }^{1.2}$ gargsangeeta11@gmail.com \\ ${ }^{2.1}$ HOD and Professor, Department of CSE, RIET, M.D. University, Rohtak, Haryana, India \\ 2.2 dr.bhupeshkumarsingh@gmail.com
}

\begin{abstract}
There has been growing interest in development of new techniques and methods for Human-Computer Interaction ( $\mathrm{HCl})$. Gesture Recognition is one of the important areas of this technology. Gesture Recognition means interfacing with computer using motion of human body typically hand movements. As a Handicapped person cannot move very easily and quickly if there is a fire in house or he/she cannot switch off the Miniature Circuit Breaker (MCB) but the same task can be done easily with hand gesture recognition. In our proposed system electrical MCB can be controlled using hand gesture recognizer. To switch on/off the MCB, we need to provide hand based gesture as an input to system.
\end{abstract}

\section{Keywords}

Hand Gesture, MCB, EmguCV, Contour.

\section{Council for Innovative Research}

Peer Review Research Publishing System

\section{Journal: INTERNATIONAL JOURNAL OF COMPUTERS \& TECHNOLOGY}

Vol.14, No. 9

www.ijctonline.com, editorijctonline@gmail.com 


\section{INTRODUCTION}

As Almost People want to save their time and effort, so they want to use the technology that can save most of the time and effort and this can be done using hand gesture recognition with various poses. Hand gesture recognition is popular for non verbal communication. The person who cannot speak but can interact with other person using different gestures such as:

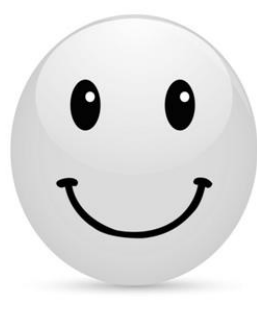

Happy

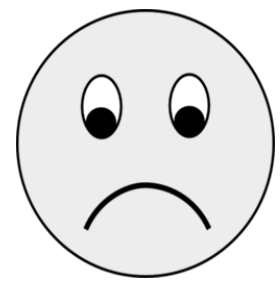

Sad

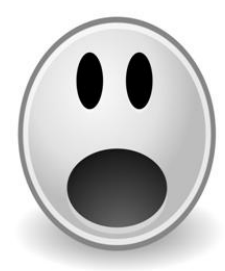

Surprised

Figure 1: Different Gestures

Hand Gesture is like a device that replaces all other remotes that are used to control electrical devices. Normally, Remotes are used for controlling devices such as TV, CD, AC, DVD player and Music System. A physically impaired person can also use hand gesture for various applications:

- To desire emotions and feelings

- $\quad$ Saving life

- To ON/OFF home appliances etc.

We have proposed System to control MCB using hand gestures and the proposed system can be used by physically impaired person in case of fire. If finger one is pointed by user, the system is used to On MCB; if finger two is pointed by User, The System is used to OFF MCB.

\section{LITERATURE REVIEW}

In the present world, the interaction with the computing devices has advanced to such an extent that as humans it has come necessity and we cannot live without it. The technology has become so embedded into our daily lives that we use it to work, shop, communicate and even entertain our self. It has been widely believed that the computing, communication and display technologies progress further, but the existing techniques may become a bottleneck in the effective utilization of the available information flow. To efficiently use them, most computer applications require more and more interaction. For that reason, human-computer interaction $(\mathrm{HCl})$ has been a lively field of research in the last few years. [1] The increase in human-machine interactions in our daily lives has made user interface technology progressively more important. Physical gestures as intuitive expressions will greatly ease the interaction process and enable humans to more naturally command computers or machines. For example, in telerobotics, slave robots have been demonstrated to follow the master's hand motions remotely. [2] People frequently use gestures to communicate. They are used for pointing to a person, to get his attention \& convey information about spatial and temporal characteristics. Gesturing does not simply embellish spoken language, but it is part of the language generation process. [3].The user should sense no appreciable delay between, when he or she makes a gesture or motion and when the computer responds. The computer vision algorithms should work for different people. Deaf people use sign language as an alternative to spoken language; it uses hand gestures which are considered by deaf people as their natural way of communication.[4]. While there is a great variety of $\mathrm{HCl}$ techniques to interact with distant virtual objects, e.g. to select menu entries, there is still a lack for intuitive and unrestricted text input. Although there are ways to input text by using a virtual keyboard on a display or by speech recognition, there are situations where both are not suitable: the rest requires interaction with a display. Users must speak which is not always possible. Demanding on the surroundings, especially for physically challenged people.[5]. Even people who can't communicate orally (sick, old or young child), they would also get benefit from this technology. It is possible to make a gesture recognition system for these people. Mobile companies are trying to make handsets which can recognize gesture and could operate from little distance also[6].Interaction between humans comes from different sensory modes like gesture, speech, facial and body expressions [2]. The main advantage of using hand gestures is to interact with computer as a non-contact human computer input modality [7].

\section{PROPOSED CONCEPT}

The Proposed System is used to control MCB using hand gesture recognition. Since a handicapped person cannot move quickly if there is a fire in a room or house but he/she can control MCB using hand gesture recognition. The basic flow of system is as follows: 


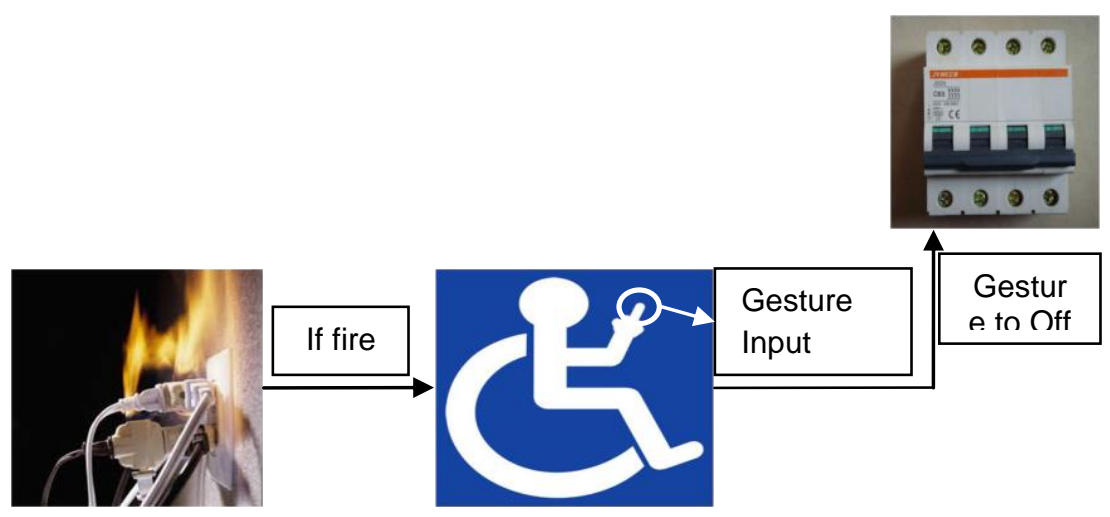

Figure 2: Flow of Proposed System

The proposed system operates in five stages as discussed below:

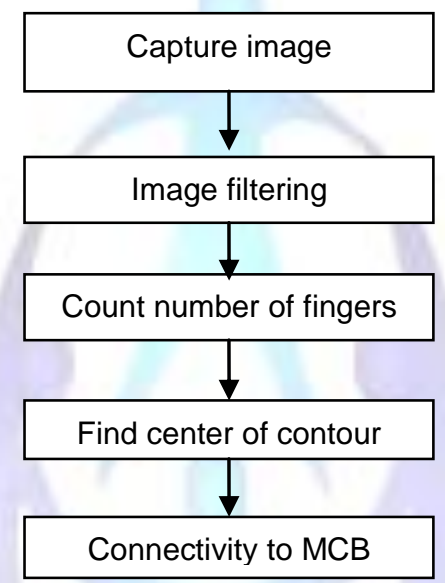

Figure 3: Stages in Proposed system

\subsection{Algorithm}

1. Capture image using EmguCv library.

2. Image filtering is applied to obtain skin colored object.

i. $\mathrm{YCbCr}$ filter is applied with required threshold $(0,255)$ to obtain skin colored part of the image.

ii. Eroding and Dilation of the filtered image is done using CV.erode() and CV.dilate() functions respectively.

iii. Smoothing of the image is done using Gaussian filter and from the resulting image, the biggest contour is extracted.

3. Next step is to count number of fingers that is done using Convexity defect method. This method determines the entire defect in our contour that is used to determine number of fingers in the image.

4. Final step is to find center of Contour. To find center of contour, we have used moment of contour method. This method is used to remove fluctuation in the center of contour.

5. To remove the problem of center shifted when palm is open or closed; we have used the condition that mouse cursor position will only be moved if the palm is closed i.e. finger is zero else mouse will remain where it was.

\section{RESULTS}

In this System, EmguCV is used for image processing and one web cam must be installed to capture the input.

The efficiency of number of fingers is shown in table:

Table 1: Efficency of input image

\begin{tabular}{|l|l|l|}
\hline Number of fingers & 1 & 2 \\
\hline Efficiency & $98 \%$ & $97 \%$ \\
\hline
\end{tabular}


The outcome of system with finger counting is shown in table:

Table 2: Outcome of Captured Image

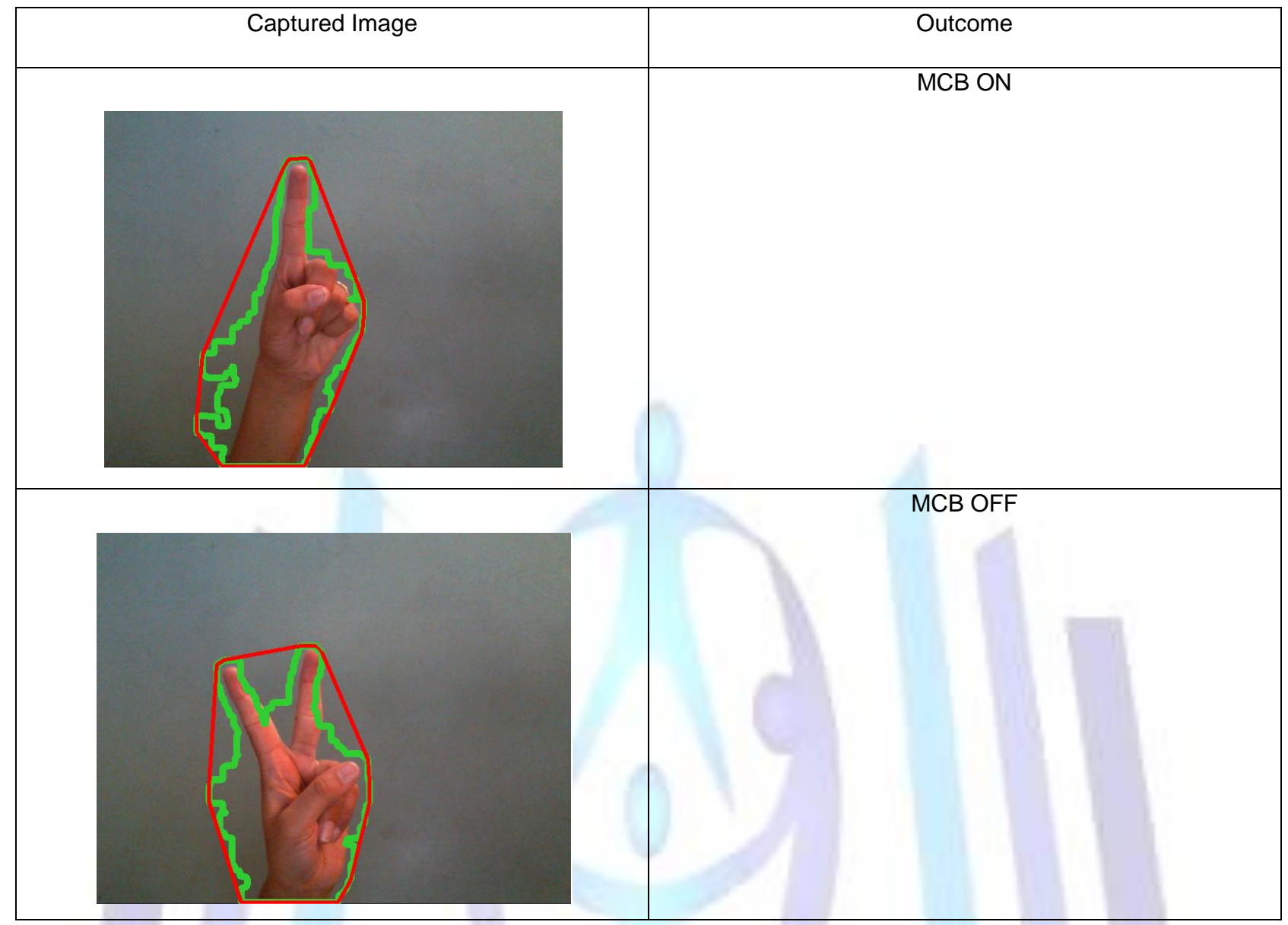

\section{CONCLUSION AND FURTHER WORK}

We have proposed system for physically impaired person to control MCB using gestures for which a web cam should be installed. We have achieved $98 \%$ efficiency in terms of complexity and $97 \%$ efficiency in terms of complex background.

In future, the proposed system can be improved by using wireless signals and circuit complexity can be also reduced at a same time.

\section{ACKNOWLEDGEMENT:}

I thank my supervisor Professor Bhupesh Kumar Singh for his guidance, advice and constant support throughout my work.

\section{REFRENCES}

1. Siddharth S. Rautaray - Anupam Agrawal, "Vision based hand gesture recognition for human computer interaction: a survey", Springer Science+Business Media Dordrecht 2012.

2. a.alice linsie, j.mangaiyarkarasi, "hand gesture recognition using mems for specially challenged people", Vol 04 , Issue 02; March - April 2013 International Journal of VLSI and Embedded Systems ISSN: 2249 - 6556, PP-238241.

3. Swapnil D. Badgujar, Gourab Talukdar, Omkar Gondhalekar, Mrs. S.Y. Kulkarni, "Hand Gesture Recognition System", International Journal of Scientific and Research Publications, Volume 4, Issue 2, February 2014, ISSN 2250-3153, PP. $1-5$.

4. Jayshree R.Pansare, Sandip Kadam, Onkar Dhawade, Pradeep Chauhan, "Real Time Static Hand Gesture Recognition System in Simple Background for Devanagari Number System", International Journal of Advanced Research in Computer Engineering \& Technology, Volume 2, Issue 3, March 2013,PP. 938-941.

5. Monuri Hemantha, M.V.Srikanth, "Simulation of Real Time Hand Gesture recognition for Physically Impaired", International Journal of Advanced Research in Computer and Communication Engineering,Vol. 2, Issue 11, November 2013, PP. 4402-4407. 
6. Ankit Chaudhary, J. L. Raheja, Karen Das, Sonia Raheja, "Intelligent Approaches to interact with Machines using Hand Gesture Recognition in Natural way: A Survey", International Journal of Computer Science \& Engineering Survey, Vol.2, No.1, Feb 2011, PP. 122-133.

7. Siddharth S. Rautaray, Anupam Agrawal, "Real time hand gesture recognition system for dynamic applications", International Journal of UbiComp, Vol.3, No.1, January 2012,PP. 21-31.

\section{Author's Biography}

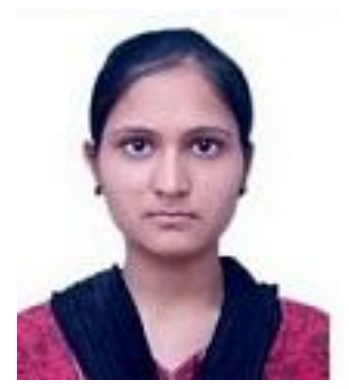

Sangeeta is currently pursuing her M.Tech. degree from Rawal College of Engineering and Technology, Faridabad. Her area of Interest is Image Processing. 